\title{
EDUCAÇÃO, POLÍTICAS PÚBLICAS E RAÇA: AÇÕES AFIRMATIVAS NO BRASIL E O ACESSO DO NEGRO AO ENSINO SUPERIOR
}

\section{ARTIGO ORIGINAL}

GUIMARÃES, Matheus De Oliveira ${ }^{1}$

GUIMARÃES, Matheus De Oliveira. Educação, políticas públicas e raça: Ações afirmativas no Brasil e o acesso do negro ao ensino superior. Revista Científica Multidisciplinar Núcleo do Conhecimento. Ano 04, Ed. 11, Vol. 01, pp. 05-21. Novembro de 2019. ISSN: 2448-0959, Link de acesso: https://www.nucleodoconhecimento.com.br/educacao/acoes-afirmativas

\section{RESUMO}

Propõe-se, por meio deste texto, uma reflexão sobre o movimento histórico de constituição do marco legal das políticas de ação afirmativa no Brasil. Busca-se aqui a apresentação de notas preambulares que, entende-se, podem ser de interessante valia para a análise, interpretação e avaliação das políticas educacionais brasileiras diretamente ligadas à temática das políticas de ação afirmativa. A partir da reflexão sobre o processo de constituição dos diplomas legais no cenário do Legislativo Federal, procura-se diagnosticar como são pensadas, discutidas e viabilizadas as ações afirmativas voltadas para a educação superior implementadas no Brasil - desde a década de 1980 até os dias atuais. Para tanto, discute-se sobre as ações afirmativas no contexto brasileiro, discorrendo-se sobre o conceito de políticas públicas, sobre

\footnotetext{
${ }^{1}$ Doutorando em Direito à Educação e Políticas Educacionais pelo Programa de PósGraduação em Educação da Pontifícia Universidade Católica de Minas Gerais (PucMinas). Mestre em Educação, vinculado à linha de pesquisa Diversidade, Inclusão e Práticas Educativas, pela Universidade Federal de Ouro Preto (UFOP). Possui graduação em Direito (UFOP), Filosofia (ICSH) e Pedagogia (FGD), com especialização em Práticas Pedagógicas (UFOP) e em Gestão de Políticas Públicas (UFOP).
} 
políticas públicas focalizadas e sobre políticas afirmativas no ensino superior. Por fim, apresenta-se uma linha cronológica da organização do marco legal das ações afirmativas no Brasil.

Palavras-Chave: Ações afirmativas, ensino superior, justiça social, legislativo federal, raça.

\section{INTRODUÇÃO}

Como resultado de sua formação social, política e econômica, que, consoante afirmam Mocelin e Martinazzo (2017) e Mocelin, Martinazzo e Guimarães (2018), privilegiou o trabalho escravo, os latifúndios e a monocultura - deixando grande parte da população excluída da riqueza socialmente produzida no país -, o Brasil configurase, até os dias de hoje, como uma nação marcadamente desigual. E essa desigualdade se desdobra em distintas dimensões, que vão do político ao social, do econômico ao cultural.

As desigualdades sociais do Brasil expressam-se mediante diferentes indicadores, por meio dos quais se percebe, para além da concentração de renda, um cenário de aguda exclusão e privação de direitos (HEILBORN; ARAÚJO; BARRETO, 2010).

De acordo com diversos autores, dentre os quais Mocelin e Martinazzo (2017), Mocelin, Martinazzo e Guimarães (2018), Heilborn, Araújo e Barreto (2010), Zoninsein e Feres Júnior (2006) e Siss (2003), o Estado brasileiro, de maneira intrincada, para que pudesse dar respostas à população quanto à suposta redução dos efeitos dessa desigualdade social estrutural, sempre utilizou-se de políticas públicas que, talvez inadequadamente, mantiveram, durante o desenvolvimento da história do país, um caráter fragmentado, assistemático e excludente que acabou por reforçar a meritocracia e a função de controle social dos trabalhadores que, de acordo com Mocelin e Martinazzo (2017), seria algo "necessário ao desenvolvimento e aprofundamento das relações sociais capitalistas, ao invés de constituir-se alicerçado em uma cultura de direitos pela ótica universalizante da cidadania e da emancipação dos sujeitos" (p.2). 
Nos termos de Behring (2009, p. 315-316, apud MOCELIN, MARTINAZZO, GUIMARÃES, 2018, p. 294),

As políticas sociais são concessões/conquistas mais ou menos elásticas, a depender da correlação de forças na luta política entre os interesses das classes sociais e seus elementos envolvidos na questão. No período de expansão, a margem de negociação se amplia; na recessão, ela se restringe.

E, para Mocelin e Martinazzo (2017) e Mocelin, Martinazzo e Guimarães (2018), esse movimento elástico das políticas sociais evidencia-se na década de 1980 "que se tornou pródiga em sua participação popular" (MOCELIN; MARTINAZZO; GUIMARÃES, 2018, p. 294), tendo em vista o início da erosão da Ditadura Militar no Brasil, somada à Lei da Anistia e aos diversos movimentos sociais. Nesse cenário, surgem as condições sociais e políticas necessárias para que velhas e novas demandas ganhem visibilidade social e, por conseguinte, entrem na agenda do Estado, o que pode ser verificado com as ações afirmativas e o debate acerca da desigualdade racial por meio do Movimento Negro (MOCELIN; MARTINAZZO, 2017).

Desde a década de 1980, diversas propostas de ações afirmativas vêm sendo construídas a partir dos movimentos sociais (sobretudo do Movimento Negro) e de ações do Legislativo, do Executivo e do próprio Judiciário (MOCELIN; MARTINAZZO; GUIMARÃES, 2018, p. 294).

Levando-se em consideração o contexto supramencionado, este texto se constrói a partir da proposição uma contextualização inaugural sobre o processo sócio-histórico de constituição das ações afirmativas no contexto brasileiro - tomando-se como sede a Lei $12.711 / 2012$ para o entendimento de que a questão racial se apresenta como uma das expressões da desigualdade social no Brasil (inclusive no que diz respeito ao acesso ao ensino superior).

Para dar conta das problematizações preliminares propostas, o texto está organizado em duas partes: uma primeira, na qual discutem-se as ações afirmativas no contexto brasileiro; e, a segunda, com uma breve exposição do marco legal das ações afirmativas no Brasil e sua formação no cenário do Legislativo Federal. 


\section{AS AÇÕES AFIRMATIVAS NO CONTEXTO BRASILEIRO}

\subsection{A PROPÓSITO DO CONCEITO DE POLÍTICAS PÚBLICAS}

Para que se compreenda de maneira adequada o contexto atual da atuação dos Estados em relação aos grupos sociais desfavorecidos, mister se faz que se esclareça o que são políticas públicas.

Afirma Elenaldo Celso Teixeira:

As políticas públicas são diretrizes, princípios norteadores de ação do poder público; regras e procedimentos para as relações entre poder público e sociedade, mediações entre atores da sociedade e do Estado. São [...] políticas explicitadas, sistematizadas ou formuladas em documentos (leis, programas, linhas de financiamentos) que orientam ações que normalmente envolvem aplicações de recursos públicos (TEIXEIRA, 2002, p. 2).

Maria das Graças Rua (1998) caracteriza as políticas públicas como obras resultantes da atividade política que abarcam o conjunto das decisões e ações atinentes à alocação imperativa de valores. A referida autora ressalta a diferença entre política pública e decisão política, informando que, enquanto aquela envolve mais do que uma deliberação e demanda diversas ações para a efetiva implementação das decisões tomadas, esta corresponde a uma escolha dentre várias, de acordo com a ordem das preferências dos atores envolvidos de forma a expressar a adequação entre os fins pretendidos e os meios disponíveis. Nesse sentido, ainda que as políticas públicas estejam intrinsecamente ligadas às decisões políticas, estas não chegam, necessariamente, a constituírem políticas públicas. Assim, nos termos de Tarcísio Ferreira (2014, p. 46), "nem todas as decisões são políticas públicas, como nem toda política pública [deriva] de decisões políticas, [ficando] clara a ideia de que nem sempre as políticas estão ligadas às decisões governamentais".

Para Giovani e Nogueira, conforme escreve Ferreira (2014), políticas públicas devem ser definidas como fatos complexos, dinâmicos e multifocais, não podendo ser reduzidas ao momento administrativo. 
Assim, ainda que, como assinalam Heilborn, Araújo e Barreto (2010), a definição do que sejam políticas públicas esteja imersa num campo controverso de discussão em razão do fato das mesmas se encontrarem em constante mutação em função das necessidades de se atender os grupos que dela necessitam, poder-se-ia caracterizálas, em consonância com Giovani e Nogueira, citados por Ferreira (2014), como formas de exercício do poder que resultam da interação entre o Estado e a sociedade. Nesse sentido, as políticas públicas tratam, em linhas gerais, da mediação estatal pela busca da promoção de justiça social (sobre a qual pesam aspectos, dentre outros, da economia, da cultura e das relações sociais).

Em consonância, Azevedo (2004) preleciona que o termo política pública deve ser compreendido como uma articulação da própria sociedade, como seu projeto, e como algo que se realiza por intermédio do Estado. São, pois, as políticas públicas, que dão visibilidade e materialidade ao Estado e, em razão disso, poderiam ser definidas como o Estado em ação (AZEVEDO, 2004).

Nesse sentido, sublinhe-se que as políticas públicas são criadas mediante a luta entre os setores sociais e as escolhas das proposições engendradas nessas políticas, dando-se como resultado do grau de enfrentamento, articulação e organização dos grupos envolvidos na relação de poder estabelecida entre esses setores sociais (AZEVEDO, 2004). E é em decorrência desse fluxo que se atinge avanços concernentes à preservação e, sobretudo, à ampliação dos direitos sociais.

\subsection{POLÍTICAS PÚBLICAS FOCALIZADAS}

A despeito do fato das políticas sociais da maioria dos países latino-americanos terem sido concebidas, em seus respectivos textos constitucionais, com base em preceitos de caráter universalizante, o uso de políticas focalizadas tem sido recorrentemente empregado na Região para a superação da pobreza.

Como preleciona Lívia Vilas-Bôas (2011), ao passo que as Constituições expandem os direitos sociais e, consequentemente, aumentam as obrigações do setor público, ocasiona-se, concomitantemente, a redução da arrecadação (que é fonte de 
financiamento das próprias políticas públicas) e o aumento da complexidade das relações intergovernamentais (entre os gestores das unidades federativas, em seus distintos níveis de atuação, em diferentes áreas sociais). Ademais, a atuação dos governos locais para a melhor identificação das necessidades sociais em países nos quais as desigualdades são latentes é imprescindível - já que as particularidades locais contribuem para a impossibilidade da solução de problemas sociais específicos com políticas genéricas.

Conforme se verifica na maioria dos textos constitucionais dos países latinoamericanos (que trouxeram, em geral, grandes avanços em termos de proteção social), a questão da focalização ou da universalização das políticas públicas não seria necessariamente um ponto a ser debatido - haja vista que ambas são necessárias em situações específicas.

A Constituição Brasileira prevê, em seu preâmbulo, a instituição de um "(...) Estado Democrático, destinado a assegurar o exercício dos direitos sociais e individuais, a liberdade, a segurança, o bem-estar, o desenvolvimento, a igualdade e a justiça como valores supremos (CF, preâmbulo). Ademais, esse mesmo Texto Constitucional aponta em seu artigo $3^{\circ}$ como um dos objetivos principais do Estado erradicar a pobreza e a marginalização e reduzir as desigualdades sociais e regionais (CF, art. $3^{\circ}$ ) e define, em seu artigo 6ํㅡㄹ uma extensa gama de direitos sociais (além de definir a própria Educação como direito de todos e dever do Estado) (CF, art. 6º).

Contudo, conquanto a maioria das Constituições latino-americanas ostentem, explicitamente, a cobertura e o acesso universais a serviços sociais (com a descentralização do financiamento), sem a adequada descentralização das competências e sem os mecanismos eficientes de controle mútuo e de coordenação entre os diferentes níveis de governo, os povos desses países ainda não podem usufruir plenamente de seus direitos (VILAS-BÔAS, 2011). Em consonância com essa autora:

A adoção de políticas sociais não é per se um problema, pois diante da existência de grupos excluídos socialmente e de recursos escassos, a focalização pode ser uma boa forma de garantir o aproveitamento mais 
eficiente destes recursos. O problema reside na importância da existência do aparato de proteção social universal para o sucesso das políticas focalizadas de assistência social que visam a superação da pobreza [...] (VILAS-BÔAS, 2011, p. 4).

Nesse sentido, até que se implementem as adequações necessárias para que se potencialize $o$ acesso universal desses povos aos serviços sociais do Estado, políticas públicas focalizadas terão a incumbência de aliviarem a pobreza e de contribuírem para a superação da situação de vulnerabilidade de boa parte da população de cada um desses países ${ }^{[2]}$.

\subsection{POLÍTICAS AFIRMATIVAS NO ENSINO SUPERIOR}

As políticas sociais caracterizam-se como intervenções do Estado, originadas de pressões sociais, com vistas à garantia dos direitos sociais.

As ações afirmativas constituem-se em "instrumento político corretivo do hiato entre o princípio constitucional da igualdade e um complexo conjunto de relações sociais profundamente hierarquizado" (SISS, 2003, p. 111). São programas ou iniciativas que tem por objetivo transferir recursos ou direitos especiais para membros de um grupo social específico, com vistas a um bem coletivo.

Enquanto políticas públicas, as ações afirmativas devem cumprir dois requisitos básicos, quais sejam: o da legalidade (que seria, em linhas gerais, a harmonia entre a ação afirmativa e o ordenamento jurídico do país no qual é implantada) e o da moralidade (que seria a explicação da ação afirmativa com base nos valores da sociedade na qual ela se insere).

O conceito de igualdade substantiva ${ }^{[3]}$ postula que a finalidade de qualquer sistema político-legal é promover a igualdade entre seus membros (e não somente submetêlo a critérios universais de igualdade formal) (FERES JÚNIOR; ZONINSEIN, 2008). E é exatamente este o fulcro normativo da ação afirmativa. Assim, tem-se que a ideia de igualdade universal formal[ ${ }^{[4]}$ é, em verdade, um dos meios ${ }^{[5]}$ para que se atinja a igualdade substantiva. 
Nesse sentido, "diante da existência de grupos excluídos socialmente e de recursos escassos, a focalização pode ser uma boa forma de garantir o aproveitamento mais eficiente destes recursos" (VILAS-BÔAS, 2011, p. 4). Quando a universalidade falha por não conseguir gerar a igualdade, por distintos motivos possíveis, medidas de discriminação positiva podem ser adotadas.

Consoante destacam Feres Júnior e Zoninsein (2008), a discriminação positiva tratase de algo que, diferentemente da maioria das relações de discriminação, visam promover seu objeto, beneficiando-o, em alguma medida, para que, em decorrência dessa ação, possa atingir a igualdade substantiva em relação aos demais.

Dentre os benefícios esperados das ações afirmativas, estão

(...) a integração de indivíduos e grupos desprivilegiados às elites da sociedade, a eliminação dos preconceitos e a discriminação contra esses indivíduos e grupos e o restante da população, os ganhos para a sociedade como um todo advindos da redução dessas desigualdades e 0 aumento da legitimidade das elites governantes frente ao restante da população (FERES JÚNIOR; ZONINSEIN, 2008, p. 19).

Partindo-se, pois, da ideia de que, do ponto de vista instrumental, exista complementariedade entre as políticas sociais universalistas orientadas para a eliminação da desigualdade social e as ações afirmativas, pode-se afirmar que, no caso das preferências criadas para a inclusão de minorias étnicas e raciais, essa complementariedade deve-se ao fato de que, tanto o racismo, quanto a discriminação racial estão articulados com a desigualdade nos ganhos das diferentes classes sociais no processo de expansão da economia capitalista que resultou na exclusão desses grupos da maioria das oportunidades criadas pela cidadania democrática (FERES JÚNIOR; ZONINSEIN, 2008, p. 20).

A partir dessa lógica, caracteriza-se o racismo como característica institucional dessas sociedades e, por conseguinte, tem-se que a soma de políticas sociais às ações afirmativas possam, em certa medida, corrigir as assimetrias sociais existentes. 


\subsection{AS POLÍTICAS DE AÇÃO AFIRMATIVA NO ENSINO SUPERIOR BRASILEIRO}

Nas duas últimas décadas, no que se refere ao tratamento da temática racial no Brasil, têm acontecido no país mudanças significativas que vêm produzindo intensas transformações na sociedade. Nesse contexto, inserem-se as ações afirmativas, entendidas como iniciativas para que se promova a inclusão social e, ao mesmo tempo, valorizem-se aspectos singulares de grupos e de indivíduos.

O tema da Educação, conforme preleciona Lima (2010), sempre recebeu destaque (tanto na atuação da militância negra, quanto nos estudos acadêmicos sobre desigualdades raciais) em razão de seu inquestionável relevo na compreensão e no enfrentamento das desigualdades (sociais e raciais) no país:

Em geral a educação é considerada e analisada como atributo individual, capital primordial no processo de realização dos indivíduos. No entanto, a compreensão das desigualdades educacionais deve tratar a educação não somente dessa perspectiva, mas também como um processo de aquisição que agrega as políticas educacionais e as características institucionais no seu modelo analítico (LIMA, 2010, p. 84).

Segundo afirma Lima (2010), as políticas educacionais brasileiras vêm buscando uma universalização tardia e acabam por coadunar com a perda da qualidade e com a expansão do sistema privado. Esse mesmo autor assevera que nas duas últimas décadas os indicadores educacionais têm melhorado para todas as faixas de ensino e em todos os grupos sociais. Contudo, ainda são observadas severas desigualdades raciais - sobretudo nos estágios mais adiantados.

A despeito do fato do debate sobre as políticas de ação afirmativa ter se concentrado, sobretudo desde a década passada, fortemente no sistema de cotas para as universidades públicas, a atuação do Estado envolve ações que vão para além das cotas - com características e escopo diferenciados.

Embora seja possível afirmar que no governo Fernando Henrique Cardoso já havia iniciativas federais voltadas à população negra, a análise dos documentos do período 
revela que a estratégia discursiva e a política deste governo foi promover o reconhecimento sem investimentos no aspecto redistributivo, embora a desigualdade fosse a principal justificativa para as políticas de valorização da população negra (LIMA, 2010, p. 81). Esse mesmo autor afirma, sobre o Governo FHC, que:

[...] as ações afirmativas que ocorreram na gestão FHC foram tímidas e posteriores a Durban. [...] as reivindicações de caráter valorativo eram prontamente atendidas pelo Estado brasileiro, uma vez que se encaixam na matriz de nacionalidade, da valorização de símbolos negros e do sincretismo das três raças fundadoras, ou seja, sem enfrentar as desigualdades raciais na distribuição de renda e no acesso aos serviços públicos (LIMA, 2010, p. 82).

O início do governo Lula, em 2003, marca uma densa mudança nas políticas com perspectiva racial. Como informa Lima (2010), até então a relação do Estado com o Movimento Negro era de exterioridade, constituindo-se, basicamente, com os atores sociais na condição de demandantes e com pouca inserção no aparato governamental. No governo Lula, essa relação se transforma a partir da incorporação, em seus quadros, de representantes negros (dando maior visibilidade às reivindicações do movimento).

As demandas por inserção da temática racial na agenda das políticas públicas de âmbito federal não são recentes - embora estudiosos dos movimentos sociais sejam categóricos ao apontarem a Constituição de 1988 como importante marco para as mudanças sociais ocorridas no país desde então. No governo Lula, o termo igualdade racial passou a ser amplamente utilizado e, inclusive, institucionalizado com a criação da Secretaria de Promoção da Igualdade Racial (SEPPIR). De uma forma geral, no que se refere à temática racial, a Carta Constitucional de 1988 introduziu a criminalização do racismo, o reconhecimento ao direito de posse de terra às comunidades quilombolas e a criação da Fundação Cultural Palmares - ações essas que, nos termos de Lima (2010, p. 79), podem ser interpretadas como resposta às reivindicações do Movimento Negro e se caracterizam por uma forma de reconhecimento (embora tais demandas fossem, sobretudo, de cunho redistributivo). 
O tema da educação superior é aquele que mais mobiliza o debate público sobre ações afirmativas - sobretudo no que se refere à implementação das políticas de cotas nas instituições públicas de ensino superior e às análises sobre os estudantes cotistas. Contudo, conforme afirma Lima (2010), a marcada reação social à política de cotas não teve a mesma repercussão quando o governo implementou um programa de ações afirmativas no sistema privado - responsável por mais de $80 \%$ das matrículas no ensino superior brasileiro ${ }^{[6]}$.

As principais políticas públicas de âmbito federal com recorte racial na educação estão organizadas, hoje, tanto na esfera do reconhecimento cultural, quanto naquela da redistribuição ${ }^{[7]}$. Destacam-se, hoje, no Brasil, além da política de cotas (muitas vezes compreendida, erroneamente, como síntese das ações afirmativas), o PROUNI (Programa Universidade Para Todos), através do qual o Governo Federal oferece bolsas de estudo (integrais e parciais) para estudantes com baixa renda para que os mesmos possam estudar em faculdades particulares; O FIES (Fundo de Financiamento Estudantil), um programa do Ministério da Educação destinado a financiar a graduação na educação superior de estudantes matriculados em instituições não gratuitas; e o PBP (Programa de Bolsa Permanência), um auxílio financeiro (oferecido pelo Governo Federal a alunos de baixa renda nas universidades públicas federais e a estudantes com bolsas integrais do PROUNI) que tem por finalidade minimizar as desigualdades sociais e contribuir para a permanência e a diplomação dos estudantes de graduação em situação de vulnerabilidade socioeconômica.

Dessas políticas, o Prouni é, por certo, a ação afirmativa de cunho redistributivo de maior impacto na história do ensino superior do país. Criado em 2004, no governo Lula, pela Medida Provisória 213/2004, o Prouni foi institucionalizado em 2005 pela Lei 11.096/2005. Esse programa tem por finalidade a concessão de bolsas de estudos integrais e parciais a estudantes de baixa renda, em cursos de graduação e sequenciais de formação específica, em instituições privadas de educação superior. São oferecidas às instituições anuídas ao Programa isenções tributárias. 
Corroborando a ideia de democratização truncada do acesso ao ensino superior a partir das ações afirmativas, preleciona Pereira (2009), referindo-se indiretamente aos resultados do Prouni:

[...] o setor privado no Brasil [responde] por $88 \%$ da oferta das vagas e por $71 \%$ das matrículas, fazendo com que ele seja um dos maiores do mundo [...]. Com o auxílio da rede privada, a oferta de vagas para o ensino superior hoje cobre $86 \%$ dos concluintes do ensino médio. [Contudo] [...] apenas $10 \%$ dos jovens na faixa de dezoito a vinte e quatro anos a estão frequentando (PEREIRA, 2009, p. 45).

Pereira (2009) acrescenta que as vagas ociosas nas IES privadas estavam, antes da implementação do Prouni, em 49,5\% - enquanto nas IES federais esse índice era de $0,9 \%$ e, nas estaduais, $4,7 \%$.

Como asseveram Feres Júnior, Daflon, Ramos e Miguel (2013), é importante que se considere que programas de ação afirmativa como o Prouni acabam por competir com os programas de inclusão das universidades públicas, direcionando a demanda de alunos pobres para as instituições privadas. Nesse sentido, partindo da informação de os estudantes de escolas públicas representam $80 \%$ dos candidatos ao ensino superior, entende-se que cabe às universidades públicas o desenvolvimento dos mecanismos necessários para que se mantenham esses estudantes em seu corpo discente (FERES JÚNIOR, DAFLON, RAMOS, MIGUEL, 2013).

Sobre as políticas de expansão da educação superior no Brasil, pode-se afirmar que o cenário econômico do país demonstra que os efeitos da democratização educacional não correspondem, necessariamente, à democratização social podendo, ao contrário, produzir outras desigualdades. (PEREIRA, 2009, p. 46).

\section{A PROPÓSITO DO ESTABELECIMENTO DO MARCO LEGAL DAS AÇÕES AFIRMATIVAS NO BRASIL}

As proposituras de projetos na esfera legislativa federal sinalizam a preocupação e o interesse de diversos parlamentares em relação à questão racial e às políticas de ação afirmativa. Consoante afirmam Mocelin, Martinazzo e Guimarães (2018, p. 299), 
Abdias Nascimento (PDT-RJ) foi o precursor desses movimento, apresentando, na década de 1980, três diferentes projetos que tratavam da criação de uma ação compensatória (PL n. 1.332/1983), da inscrição da discriminação como crime de lesahumanidade (PL n. 1.661/1983) e da reserva de vagas no vestibular para negros (PL n. 3.196/1984) - respectivamente.

Ainda na década de 1980, Carlos Alberto Caó (PDT-RJ) propôs que se definisse o racismo como crime (PL n. 668/1988 - transformado na Lei Ordinária n. 7.716/1989 por José Sarney).

$\mathrm{Na}$ década de 1990, pelo menos outros nove projetos foram apresentados no Senado Federal no sentido de promover ações que reduzissem o distanciamento entre as desigualdades decorrentes da raça. Florestan Fernandes (PT-SP), em 1993, propõe a PEC n. 008583-6, discutindo diretamente a questão dos negros - Título VIII (Da Ordem Social), Capítulo IX (Dos Negros). Benedita da Silva (PT-RJ), em 1995, propõe o PL n. 13 e o PL n. 14, dispondo ambos, respectivamente, sobre a instituição de cota mínima de vagas em instituições públicas para alunos carentes e para os setores etnorraciais socialmente discriminados. Nesse mesmo ano, Paula Paim (PT-RS) propõe o PL n. 1.239/1995, que defendia a garantia de indenização para os descendentes de escravos no Brasil. Em 1998, Luiz Alberto (PT-BA) propõe os projetos de lei n. 4.567 e 4.568 que criariam, respectivamente, o Fundo Nacional para o Desenvolvimento de Ações Afirmativas (FNDAA) e o Conselho Nacional de Promoção da Igualdade de Oportunidades (CNPIO). Em 1999, três importantes projetos de lei são propostos no Legislativo Federal: o primeiro (PL n. 73) por Nice Lobão (PFL-MA), que dispõe sobre o ingresso nas universidades federais e estaduais; o segundo (PL n. 259) por Esther Grossi (PT-RS) e Bem-Hur Ferreira (PT-MS), que dispõe sobre a obrigatoriedade da inclusão da temática da História e Cultura AfroBrasileira no currículo oficial da Rede de Ensino; e o terceiro (PL n. 298) por Antero Paes de Barros (PSDB-MT), que propõe o estabelecimento de reserva de vagas nas universidades para egressos da rede pública de ensino (MOCELIN; MARTINAZZO; GUIMARÃES, 2018, p. 300-301). 
Já nos anos 2000, Fernando Henrique Cardoso cria o Programa Diversidade na Universidade (MP n. 63/2002), que é convertida na Lei n. 10.558/2002 de Ramez Tebet. Em 2003, Luiz Inácio Lula da Silva transforma o PL 259/1999 em lei ordinária (Lei 10.639/2003). Em 2005, Paulo Paim propõe o PL n. 6.264/2005, que institui o Estatuto da Igualdade Racial. Em 2010, Luiz Inácio Lula da Silva sanciona a Lei $n$. 12.288/2010 - transformando o Estatuto da Igualdade Racial (PL n. 6.264/2005) em lei ordinária. Em 2012, Dilma Rousseff sanciona a Lei 12.711 (convertendo o PL 73/1999 em lei ordinária). Em 2013, Dilma Rousseff propõe o PL 6.738, que dispõe sobre a reserva de percentual de vagas para negros em concursos públicos e, já no ano seguinte, o mesmo é convertido na Lei 12.990/2014. Em 2015, através do PL n. 46, Cássio Rodrigues da Cunha Lima (PSDB-PB) propõe a alteração da Lei 12.711 para que se inclua as pessoas com deficiência. Em 2016, Michel Temer sanciona a Lei n. 13.409, transformando em lei ordinária o PL n. 46/2015 (MOCELIN; MARTINAZZO; GUIMARÃES, 2018, p. 300-301).

A maioria dos projetos supramencionados justificaram-se por meio da referência da educação como instrumento de redução das desigualdades sociais e de promoção de justiça social.

\section{CONSIDERAÇÕES FINAIS}

O Brasil, por caracterizar-se por inúmeras desigualdades, sobretudo de ordem social com marcada influência da raça, deve buscar remediar essas assimetrias com a implementação de ações afirmativas.

Como alega Ferreira (2010), a modernidade, ao chegar ao Brasil, encontrou um país com marcas de conservadorismo e tradicionalismo - uma situação que, de certa forma, mantêm-se até hoje em variados setores sociais. No Brasil, o preconceito e a exclusão racial se deram (e ainda se conservam) de forma velada, não institucionalizada e não reconhecida abertamente. Isso compromete, em muitos casos, os processos de tomada de ação por parte do poder público. Ações como as políticas de ação afirmativa, ainda que recorrentemente vistas como afronta à 
igualdade de oportunidades, devem ser utilizadas como instrumentos de combate à desigualdade, à segregação e ao preconceito.

As políticas de ação afirmativa enquadram-se, pois, como importante remédio contra as injustiças sociais.

\section{REFERÊNCIAS}

ANDREWS, George Reid. Ação afirmativa: um modelo para o Brasil? In: SOUZA, J. (Org.). Multiculturalismo e racismo: uma comparação Brasil-Estados Unidos. Brasília: Paralelo 15, 1997. p. 137-144.

APPLE, Michael W. A educação pode mudar a sociedade?. Petrópolis: Vozes, 2017.

APPLE, Michael W.; BALL, Stephen J.; GANDIN, Luís Armando. Mapeamento da sociologia da educação: contexto social, poder e conhecimento. In: Sociologia da Educação: análise internacional. Michael W. Apple; Stephen J. Ball; Luís Armando Gandin (orgs.). Porto Alegre: Penso, 2013.

AZEVEDO, Janete Maria Lins de. A educação como política pública. 3. ed. Campinas, Autores Associados, 2004.

AZEVEDO, Janete Maria Lins de. Impasses e perspectivas para a descentralização de políticas de educação. Em Aberto, Brasília, ano 7. n 39, jul./set. 1988.

BOVERO, Michelangelo. Contra o governo dos piores: uma gramática da democracia. Rio de Janeiro: Campus, 2002.

BRASIL. Constituição (1988). Constituição da República Federativa do Brasil. Brasília, DF: Senado Federal: Centro Gráfico, 1988. 292 p.

BRASIL. Decreto no 65.810, de 8 de dezembro de 1969. Promulga a Convenção Internacional sobre a eliminação de todas as formas de discriminação racial. Diário Oficial, Brasília, DF, 8 dez. 1969. 
BRASIL. Decreto $n^{\circ}$ 7.824, de 11 de outubro de 2012. Promulga a Convenção Internacional sobre a eliminação de todas as formas de discriminação racial. Diário Oficial, Brasília, DF, 11 out. 2012.

BRASIL. Lei $n^{\circ}$ 12.711, de 29 de agosto de 2012. Dispõe sobre o ingresso nas universidades federais e nas instituições federais de ensino técnico de nível médio e dá outras providências. Diário Oficial, Brasília, DF, 30 ago. 2012.

BRASIL. Lei $n^{\circ}$ 9.394, de 20 de dezembro de 1996. Estabelece as diretrizes e bases da educação nacional. Diário Oficial, Brasília, DF, 23 dez. 1996.

BRASIL. Portaria Normativa $n^{\circ}$ 18, de 11 de outubro de 2012. Dispõe sobre a implementação das reservas de vagas em instituições federais de ensino de que tratam a Lei oㅜ 12.711, de 29 de agosto de 2012, e o Decreto oㅜ 7.824, de 11 de outubro de 2012. Diário Oficial, Brasília, DF, 15 out. 2012.

BRASIL. Projeto de Lei $n^{\circ}$ 180, de 2008. Dispõe sobre o ingresso nas universidades federais e estaduais e nas instituições federais de ensino técnico de nível médio e dá outras providências. Deputada Nice Lobão.

CURY, Carlos Roberto Jamil. Cidadania e Direitos Humanos. In: VEIGA, Cynthia Greive (org.) Carlos Roberto Jamil Cury: Intelectual e Educador. Belo Horizonte: Autêntica, 2010.

CURY, Carlos Roberto Jamil. Direito à Educação: direito à igualdade, direito à diferença. In: VEIGA, Cynthia Greive (org.) Carlos Roberto Jamil Cury: Intelectual e Educador. Belo Horizonte: Autêntica, 2010.

DAFLON, Verônica Toste; FERES JÚNIOR, João; MORATELLI, Gabriela. Levantamento das políticas de ação afirmativa 2014: evolução temporal e impacto da Lei no 12.711 sobre as universidades federais (IESP-UERJ), n. 4, 2014. 
FERES JÚNIOR, João. Aspectos Normativos e Legais das Políticas de Ação Afirmativa. In: FERES JÚNIOR, JOÃO. Ação Afirmativa e Universidade: experiências nacionais comparadas. Brasília: Universidade de Brasília, 2006.

FERES JÚNIOR, João; DAFLON, Verônica; RAMOS, Pedro; MIGUEL; Lorena. O impacto da Lei no 12.711 sobre as universidades federais. Levantamento das políticas de ação afirmativa (GEMAA), IESP-UERJ, setembro, 2013.

FERREIRA, M. C. C. Sobre Inclusão, Políticas Públicas e Práticas Pedagógicas. In: GÓES, M. C. R.; LAPLANE, A. L. F. (Org) Políticas e práticas de educação inclusiva. 3a. Ed. Campinas: Autores Associados, 2007.

FERREIRA, Tarcísio José. Um olhar sobre as políticas públicas afirmativas educacionais. Projeção, Direito e Sociedade, v. 5, n. 1, p. 45-63. 2014.

FERREIRA, Wallace. Justiça e Reconhecimento em Nancy Fraser. Teresina: Jus Navigandi, 2012.

FRASER, Nancy. From Redistribution to Recognition? Dilemmas of Justice in a "Postsocialist" Age. In. Adding Insult to Injury. Nancy Fraser debates her critics. Edinburgh: Verso, 2008.

HEILBORN, Maria Luiza; ARAÚJO, Leila; BARRETO, Andreia (Orgs). Gestão de Políticas Públicas em Gênero e Raça: GPP-GeR, Módulo I. Rio de Janeiro: CESPE; Brasília: Secretaria de Políticas Públicas para as Mulheres. 2010.

HERINGER, Rosana. Panorama das ações afirmativas no Brasil a partir de 2001. In: FERES JÚNIOR, JOÃO. Ação Afirmativa e Universidade: experiências nacionais comparadas. Brasília: Universidade de Brasília, 2006.

KERSTENETZKY, C. L. Políticas Sociais: focalização ou universalização. Revista de Economia Política, v. 26, n. 4. São Paulo, 2014.

LIMA, Márcia. Ações afirmativas no governo Lula. In: Revista Novos Estudos. 2010. 
MOCELIN, C. E.; MARTINAZZO. A trajetória histórica das ações afirmativas e o serviço social: reflexões a partir da constituição de seu arcabouço legal. UNIJUÍ: 2017. Salão do Conhecimento.

MOCELIN, C. E.; MARTINAZZO, C. J.; GUIMARÃES. A trajetória histórica da constituição do marco legal das ações afirmativas. Vitória: Argumentum. V. 10, n. 1, p. 293-308, jan./abr. 2018.

OLIVEIRA, Nythamar de. Affirmative action, recognition, self-respect. Axel Honneth and the phenomenological deficit os critical theory. Porto Alegre: Civitas, 2009.

PEREIRA, Elisabete Monteiro de Aguiar. A universidade da modernidade nos tempos atuais. Revista Avaliação, v. 14, n. 1, p. 29-52. Campinas, 2009.

RUA, Maria das Graças. Análise de Políticas Públicas: Conceitos Básicos. In: RUA, Maria das Graças; VALADÃO, Maria Izabel. O Estudo da Política: Temas Selecionados. Brasília: Paralelo 15, 1998.

SISS, Ahyas. Afro-Brasileiros, Cotas e Ação Afirmativa: razões históricas. Niterói: PENESB, 2003.

SOUZA SANTOS, Boaventura de. A Crise dos Paradigmas em Ciências Sociais e os Desafios para o Século XXI. Rio de Janeiro: Ed. Contraponto/Corecon, 1999.

TEIXEIRA, Elenaldo Celso. O Papel das Políticas Públicas no Desenvolvimento Local e na Transformação da Realidade. Revista Políticas Públicas - AATR-BA, 2002.

VILAS-BÔAS, Lívia. A Focalização e Universalização na Política Social Brasileira: opostos e complementares. Center for Studies on Inequality and Development, CEDE, p. 1-19. 2011.

ZONINSEIN, Jonas; FERES JÚNIOR, João. Ação Afirmativa e Desenvolvimento. In: FERES JÚNIOR, João \& ZONINSEIN, Jonas (Orgs.). Ação Afirmativa e Universidade: experiências nacionais comparadas. Brasília: Editora Universidade de Brasília, 2006. 
ZONINSEIN, Jonas; FERES JÚNIOR, João. Ação Afirmativa no Ensino Superior Brasileiro. Belo Horizonte: Editora UFMG, 2008.

\section{APÊNDICE - REFERÊNCIAS DE NOTA DE RODAPÉ}

2. Ainda que se saiba que mesmo os programas focalizados implementados nesses países não sejam efetivamente eficientes por não conseguirem, de maneira geral, atenderem todas as populações elegíveis. Conforme preleciona Vilas-Bôas (2011, p. 4): "(...) quanto mais criterioso o programa, maiores serão os custos da sua administração impondo, assim, um dilema ao formulador da política focalizada. Dessa forma, a definição dos critérios de elegibilidade do programa acaba implicando na inclusão ou exclusão indevidas". Se o erro de inclusão reduz, por um lado, a eficiência do programa, por outro, o erro de exclusão não atende parte da população-alvo (VILAS-BÔAS, 2011).

3. Também é utilizado pela doutrina o termo igualdade material - com o mesmo sentido de igualdade substantiva.

4. Aqui, a igualdade universal formal seria, em termos rasos, a igualdade legal (aquela através da qual todos seriam iguais perante a Lei).

5. Há outros meios legais para que se alcance a igualdade que dependem da universalidade da norma, seguindo o princípio da não-discriminação.

6. De acordo com o Censo da Educação Superior, em 2014, 87,4\% das instituições de educação superior são privadas.

7. Dentre essas, destaca-se o Prouni (Programa Universidade Para Todos).

Enviado: Outubro, 2019.

Aprovado: Novembro, 2019. 